\title{
Risk behaviour of street children in Colombo
}

\section{B C V Senaratna ${ }^{1}$, B V N Wijewardana ${ }^{2}$}

(Index words: street children, health, risk behaviour, Sri Lanka)

\begin{abstract}
Introduction Sri Lankan street children live in insecure and disadvantaged environments and have disrupted and poorly functioning families resulting in their poor socialisation. In this backdrop they are at high risk of adopting delinquent and antisocial behaviour and becoming victims of abuse. Despite recognition of this as a social problem, an in-depth exploration of their behaviour and its correlates has not been attempted.
\end{abstract}

Objectives To describe risk behaviour among street children in Colombo city and the determinants of such behaviour.

Methods A cross sectional qualitative study in Colombo Fort, Pettah, Slave Island, and Maradana areas was conducted using focus group discussions (FGDs) with street children and semi-structured interviews (SSIs) with street children and key informants in their environment. Data generated were used to profile 283 children identified through referral sampling. An observation study was conducted to validate data generated through FGDs and SSIs. Semi-structured questionnaires, a moderator guide, an interviewer-administered questionnaire, and an observational checklist were used for SSIs, FGDs, profiling, and observational study, respectively.

Results Majority of street children were boys and were aged 14 years or less. Nearly $18 \%$ lived alone without a guardian. Two thirds had never enrolled in a school. Many children were used for begging, neglecting their health vulnerabilities. Occupational risk behaviour included heavy manual labour, transportation and sale of illicit alcohol and narcotics, robbing/pick-pocketing, commercial sex work, and pimping. Recreational risk behaviour included abuse of alcohol/narcotics, smoking, sexual promiscuity, and patronising commercial sex workers.

Conclusions Increased awareness and strategies are required to minimise threats to street children and society.

Ceylon Medical Journal 2012; 57: 106-111

Departments of ${ }^{1}$ Community Medicine and ${ }^{2}$ Criminology University of Sri Jayewardenepura, Sri Lanka.

Correspondence: BCVS, e-mail: <chamaravs@yahoo.com>. Received 5 March and revised version accepted 19 May 2012. Competing interests: none declared. 


\section{Introduction}

The global population of street children has been variously estimated to range from tens of millions to 100 million with numbers rising daily and a large proportion living in South Asia [1-3]. In 2006, the estimated number of street children in Sri Lanka was 15,000 [4]. Majority of them live in the Colombo city, which is the former capital and a busy commercial hub, and fulfils environmental requirements for their sustenance.

Street children are considered a social problem [4]. In addition to obtaining provision from parents or guardians, they also earn their own income by legal as well as socially unacceptable and/or illegal means [5]. In the backdrop of the insecure and disadvantaged environments they live in, these children are at high risk of adopting delinquent behaviour and becoming victims of abuse [4-7]. Experiencing deviant behaviour in their environment and lack of normally functioning families results in their poor socialisation $[4,5]$.

Street children worldwide adopt a wide range of risk behaviour, commonest of which include risky sexual practices, alcohol and substance abuse, and violence [814]. Extreme poverty, lack of appropriate care by adults, been victims of violence, and substance abuse have been repeatedly shown to be common determinants of delinquent and anti-social behaviour of street children [2, $4,8]$. Nevertheless, street children in different regions and countries have unique behaviour patterns and determinants shaped by distinctive socio-cultural and economic environments in their respective societies [1415]. However, in-depth explorations of risk behaviour of Sri Lankan street children and analysis of determinants of such behaviour are scarce $[4,16]$.

Recognising street children as a social problem, lawenforcement authorities of Sri Lanka continue to take punitive actions against delinquent behaviour of these children $[4,16]$. Unfortunately, such litigations do not act as deterrents $[2,4,16]$. In order to protect street children as well as society from any harm originating from such delinquent and anti-social behaviour, an in-depth understanding of such behaviour and their determinants are imperative. We conducted this study to describe risk behaviour and determinants of such risk behaviour among street children in Colombo city.

\section{Methods}

We carried out this qualitative, cross-sectional study (in three phases) in Colombo Fort, Pettah, Slave Island and Maradana areas of Colombo City. For purposes of this research, we defined street children as children living on street most of time regardless of whether they still maintained some contact with their families or not [10].

In Phase I, we conducted twenty semi-structured interviews (SSIs) with key informants (KIs - including parents/guardians of street children, street vendors/ persons working in boutiques in areas frequented by street children, and social workers/researchers who have working experience regarding street children). They were identified through prior knowledge.

In Phase II, we recruited street children for research using referral sampling. Focus group discussions (FGDs) were conducted with recruited children until no new information was forthcoming (ten FGDs, each with 8-10 children, aged $8-<18$ years). We also conducted SSIs with 25 children, selected to represent their variability in age, sex, ethnic group and religious group. In Phase III, we profiled all recruited children using variables generated through SSIs and FGDs.

We used two pre-piloted, interviewer-administered, semi-structured questionnaires to conduct SSIs with KIs and street children. A pre-piloted, moderator's question guide was used to moderate FGDs. An intervieweradministered questionnaire was used for profiling. All interviewers had prior experience in studies/programmes involving street children, and therefore had a good rapport with participants. SSIs and FGDs were tape recorded with consent of participants whenever possible, and notes were taken down. Tapes were transcribed and notes expanded immediately after each SSI and FGD. Data were analysed using qualitative content analysis. We observed children's behaviour using a pre-piloted behaviour checklist and these data were used to validate information that emerged from SSIs and FGDs.

Informed consent was obtained from all participants, including children. In addition, informed consent of parents/guardians was also obtained for participation of their children. Ethical approval was obtained from Ethical Review Committee of Faculty of Medical Sciences, University of Sri Jayewardenepura. Whenever children were in need of support services from health, social services, or any other sector, we referred them to relevant sectors.

\section{Results}

KIs included 6 parents/guardians, 6 street vendors, 5 persons working in boutiques, and 3 social workers/ researchers. Our sample included 283 children (of-street $\mathrm{n}=102 ; 36 \%$ and on-street $\mathrm{n}=181 ; 64 \%$ ) representing all major ethnic and religious groups. Nearly $62 \%$ were aged 14 years or less. Majority were boys. Around $40 \%$ lived either with one or both parents, but nearly $18 \%$ lived alone. Two thirds had never enrolled in a school (Table 1).

Despite diversity of social, demographic, cultural and economic strata these children represent, they shared common socio-economic disadvantages, and valued delinquent behaviour over traditional social norms and values. Social prestige is usually bestowed upon a street child based on a set of mostly anti-social behaviour demonstrated by that child. On the other hand, their lifestyle, and at times their very survival, is closely tied to such risk behaviour which are means of their sustenance. However, they also use some risk behaviour as recreations. 
Table 1. Basic socio-demographic data of the contacted street children

\begin{tabular}{|c|c|c|c|}
\hline & $\begin{array}{c}\text { Female } \\
(n=73)\end{array}$ & $\begin{array}{c}\text { Male } \\
(n=210)\end{array}$ & $\begin{array}{c}\text { Total } \\
(n=283)\end{array}$ \\
\hline \multicolumn{4}{|l|}{ Age } \\
\hline 10 years or less & $33(45.2 \%)$ & $46(21.9 \%)$ & $79(27.9 \%)$ \\
\hline $11-12$ years & $14(19.2 \%)$ & $32(15.2 \%)$ & $46(16.2 \%)$ \\
\hline $13-14$ years & $17(23.3 \%)$ & $33(15.7 \%)$ & $50(17.7 \%)$ \\
\hline $15-16$ years & $5(6.8 \%)$ & $58(27.6 \%)$ & $63(22.3 \%)$ \\
\hline $17-<18$ years & $4(5.5 \%)$ & $41(19.5 \%)$ & $45(15.9 \%)$ \\
\hline \multicolumn{4}{|l|}{ Ethnicity } \\
\hline Sinhala & $31(42.5 \%)$ & $74(35.2 \%)$ & $105(37.1 \%)$ \\
\hline Tamil & $23(31.5 \%)$ & $5626.7 \%)$ & $79(27.9 \%)$ \\
\hline Moor & $14(19.2 \%)$ & $57(27.1 \%)$ & $71(25.1 \%)$ \\
\hline Other & $5(6.8 \%)$ & $23(10.9 \%)$ & $28(9.9 \%)$ \\
\hline \multicolumn{4}{|l|}{ Religion } \\
\hline Buddhist & $30(41.1 \%)$ & $65(30.9 \%)$ & $95(33.6 \%)$ \\
\hline Hindu & $20(27.4 \%)$ & $50(23.8 \%)$ & $70(24.7 \%)$ \\
\hline Islam & $18(24.7 \%)$ & $71(33.8 \%)$ & $89(31.4 \%)$ \\
\hline Catholic/Christian & $3(4.1 \%)$ & $16(7.6 \%)$ & $19(6.7 \%)$ \\
\hline Other & $2(2.7 \%)$ & $8(3.8 \%)$ & $10(3.5 \%)$ \\
\hline \multicolumn{4}{|l|}{ Lives with } \\
\hline Both parents & $7(9.6 \%)$ & $10(4.8 \%)$ & $17(6.0 \%)$ \\
\hline Mother only & $13(17.8 \%)$ & $57(27.1 \%)$ & $70(24.7 \%)$ \\
\hline Father only & $8(11.0 \%)$ & $20(9.5 \%)$ & $28(9.9 \%)$ \\
\hline Non-parent partner of mother or father & $5(6.8 \%)$ & $15(7.1 \%)$ & $20(7.1 \%)$ \\
\hline Grand parent & $14(19.2 \%)$ & $17(8.1 \%)$ & $31(10.9 \%)$ \\
\hline Aunt / uncle & $6(8.2 \%)$ & $11(5.2 \%)$ & $17(6.0 \%)$ \\
\hline Sibling/s & $12(16.4 \%)$ & $8(3.8 \%)$ & $20(7.1 \%)$ \\
\hline Neighbour & $3(4.1 \%)$ & $16(7.6 \%)$ & $19(6.7 \%)$ \\
\hline Others & $3(4.1 \%)$ & $8(3.8 \%)$ & $11(3.9 \%)$ \\
\hline None & $2(2.7 \%)$ & $48(22.8 \%)$ & $50(17.7 \%)$ \\
\hline \multicolumn{4}{|l|}{ Level of education } \\
\hline Never enrolled in school & $52(71.2 \%)$ & $128(61.0 \%)$ & $180(63.6 \%)$ \\
\hline Completed 1-5 years of schooling & $18(24.7 \%)$ & $53(25.2 \%)$ & $71(25.1 \%)$ \\
\hline Completed 6-10 years of schooling & $3(4.1 \%)$ & $29(13.8 \%)$ & $32(11.3 \%)$ \\
\hline
\end{tabular}

Table 2. Risk behaviour adopted by street children due to occupations

\begin{tabular}{|c|c|c|c|}
\hline Risk behaviour & $\begin{array}{l}\text { Female } \\
\left(n=73^{*}\right)\end{array}$ & $\begin{array}{c}\text { Male } \\
\left(n=210^{*}\right)\end{array}$ & $\begin{array}{c}\text { Total } \\
\left(n=283^{*}\right)\end{array}$ \\
\hline Begging & $18(42.7 \%)$ & $48(22.9 \%)$ & $66(23.3 \%)$ \\
\hline Heavy manual labour & - & $20 \quad(9.5 \%)$ & $20 \quad(7.1 \%)$ \\
\hline Light manual labour** & $15(20.6 \%)$ & $39(18.6 \%)$ & $74(26.2 \%)$ \\
\hline Legal trades activities** & $24(32.9 \%)$ & $88(41.9 \%)$ & $112(39.6 \%)$ \\
\hline Transportation and sale of illicit alcohol and narcotics & $19(26.0 \%)$ & $90(42.9 \%)$ & $109(38.5 \%)$ \\
\hline Pick-pocketing / stealing / robbing & $17(23.3 \%)$ & $52(24.8 \%)$ & $69(24.4 \%)$ \\
\hline Commercial/Survival sex work & $18(24.7 \%)$ & $42(20.0 \%)$ & $60(21.2 \%)$ \\
\hline Pimping & $2(2.7 \%)$ & $47(22.4 \%)$ & $49(17.3 \%)$ \\
\hline
\end{tabular}

* Many children engage in multiple risk occupations.

** Only underage children are included. 
Table 3. Risk behaviour adopted by street children as means of frequent recreations

\begin{tabular}{lrrr}
\hline & $\begin{array}{c}\text { Female } \\
(n=73 *)\end{array}$ & $\begin{array}{c}\text { Male } \\
(n=210 *)\end{array}$ & $\begin{array}{c}\text { Total } \\
(n=283 *)\end{array}$ \\
\hline Risk behaviour & $10(13.7 \%)$ & $169(80.5 \%)$ & $179(63.2)$ \\
Abuse of alcohol & $4(5.5 \%)$ & $153(72.9 \%)$ & $157(55.5 \%)$ \\
Abuse of narcotic substances (including cannabis) & $2(2.7 \%)$ & $178(84.8 \%)$ & $180(63.6 \%)$ \\
Smoking & $6(8.2 \%)$ & $163(77.6 \%)$ & $173(82.4 \%)$ \\
Use of pornography & $25(34.2 \%)$ & $78(37.1 \%)$ & $103(36.4 \%)$ \\
Promiscuous sexual activities & - & $74(35.2 \%)$ & $74(26.2 \%)$ \\
Patronising CSWs & & & $(2 \%)$ \\
\hline
\end{tabular}

* Many children engage in multiple risk behaviours as recreations.

\section{Occupational risk behaviour}

Many children engage in (at times forced to by their adult carers) risk behaviour to earn a living. Younger children are mostly used in begging, which is hidden due to legal restrictions, but nevertheless ongoing. These children are not provided with adequate nutrition, and their health conditions are not given due attention as doing so would render these children useless for begging. “...uncle didn't give medicine (to child). If cured, people won't give money” - SSI (child) 3 .

Child labour, which is a form of child abuse, is common among street children. They engage in a variety of manual labour, ranging from light activities (e.g. helping adults to wheel carts) through cleaning of shops/market places/ toilets to heavy manual labour (e.g. lifting and carrying heavy loads). They also sell commercial items such as vegetables, fruits, betel and newspapers "Sometimes I thought (that) I would die of weight (of the load carried)", - SSI (child) 17.

Although many children are forced by adult carers to these activities, majority of them, especially those who do not have (or not cared-for by) adult-carers, chose by themselves to engage in these activities for survival. In addition, children also work as pimps for commercial sex workers (CSWs) of Colombo city. Some children, including boys, themselves function as CSWs or survival sex workers (SSWs). Further, children are also used as a medium for transportation and sale of illicit alcohol and narcotic substances by drug dealers. "... he forced me to do things (sexual acts), and gave money... Later I continued for money" - SSI (child) 6. "Police don't think we carry drugs. Therefore no checking... We also get drugs free” - FGD 4.

Pick-pocketing and robbing are also common occupations of street children, which are conducted either alone or in collaboration with others. Both girls and boys are used for begging. However, engagement in manual labour, transportation and sale of illicit alcohol and narcotics, and pimping are commoner among boys (Table 2).

\section{Recreational risk behaviour}

There is a gender difference in recreational risk behaviour (Table 3). Abuse of alcohol and narcotic substances is widespread among boys but less among girls. Smoking cigarettes and cannabis, which are equally prevalent, is a practice exclusively of boys with rare exceptions. Sexual promiscuity is common among both male and female adolescents and includes male homosexual behaviours. Boys patronise CSWs at times. Usage of pornography is commoner among boys. "Nobody cares whom they (children) have sex with... I have slept with sixteen already" - FGD 4. "We get free drugs and free sex. It is good life" - FGD 8.

\section{Other risk behaviour}

These children, especially boys, often encounter violence. As a rule, most boys live in 'gang's which are tightly knit and function based on their own rules and norms. Entry into gangs is difficult, and membership is guarded. These gangs facilitate peddling of illicit alcohol and narcotic substances. In order to protect such financial interests of gang membership the gangs display territorial behaviour, which at times leads to violent encounters with other gangs. "how could they operate in our area? ... One day, we ambushed them and cut (them) with razor knives"- FGD 9.

\section{Correlates of risk behaviour}

Extreme poverty, socio-cultural and peer pressures, and low educational achievements are considered as important factors promoting risk behaviour. Lack of families/guardians and inadequate family support and attachment to alternative value systems in their culture are also considered as risk factors. Most children consider risk behaviour as their recreational activities. Lack of acceptable recreations for these children promotes such behaviour as recreations.

\section{Discussion}

Children's appreciation of delinquency over traditional values probably results from the street culture which disregards the latter [4]. Difficult and disadvantaged socio-economic background of Colombo's street children 
forces them to adopt risk behaviour as in other parts of the world [17-19]. Most risk behaviour is essentially coupled with their sources of sustenance, effectively preventing them from seeking alternatives. Some employers violate the law by offering employment to underaged children. Law enforcement in this regard has been inadequate $[4,16]$. Most occupations, especially those which involve manual labour and drug peddling, make them vulnerable to physical and mental abuse, and it is vital that state/non-state partnerships be developed to monitor children in occupations and ensure their safety.

Pimping makes children vulnerable to risky sexual behaviour and encourages them to patronise CSWs [4, 16]. This and children practicing as CSWs/SSWs, especially as male CSWs/SSWs, endangers their health by increasing the risk of contracting HIV and hepatitis B [16]. Colombo's underworld and drug dealers increasingly exploit children for their benefit, which places these children at risk of substance and alcohol abuse, resulting addiction, and becoming victims of violence $[4,16]$. This is confirmed by the comparatively high proportion of street children who frequently smoke and abuse alcohol and narcotic substances [19].

An important factor associated with risk behaviour is the disadvantaged socio-economic background from which these children originate, which sequentially leads to further disadvantaged socio-cultural situations. They are from families of extreme poverty with low educational achievements. Family disruptions are common in such settings, leading to poor family support and inadequate care and supervision by available carers [23]. This in turn forces children to fend for themselves. Norms of their social environment also promote risk behaviour. In a culture which has scanty regard for normal social values, anti-social behaviour is considered prestigious. Coupled with gang behaviour and peer pressure, this encourages children to partake in risk activities [4].

A major limitation in our study is the sampling method used. Due to the nature of the study population it was not possible to use any form of random sampling which would have increased external validity of results. Nevertheless, we have attempted to capture most of the study population through extensive referring, to minimise this bias.

\section{Conclusion}

Street children in Colombo city exist in a hidden social interface with complex risk factors and engage in risk behaviour that endangers themselves and society. Appropriate policies, policy tools and strategies which would involve multiple stakeholders, need to be introduced to minimise such threats.

\section{Acknowledgements}

Human and material resources were provided by Centre for Community Health.

\section{References}

1. United Nations Children's Fund (UNICEF). The State of World's Children: Excluded and Invisible. 2006, UNICEF: New York.

2. Benítez STD. State of World's Street Children: Violence, in Save the Children series. 2007, Consortium for Street Children (UK): London.

3. West A. At the Margins: Street Children in Asia and the Pacific, in Poverty and Social Development Papers. 2003, Regional and Sustainable Development Department, Asian Development Bank.

4. Wijewardana BVN. Deviant behaviours of street children; with special reference to Colombo Fort and Pettah (in Sinhala). Faculty of Graduate Studies, University of Sri Jayewardenepura: Colombo, 2008.

5. Glauser B. Street children: deconstructing a construct. Constructing and Reconstructing Childhood: Contemporary Issues in the Sociological Study of Childhood, ed. A. James and A. Prout. 1990, Philadelphia: The Falmer Press. 138156.

6. Quiroga J. Torture in children. Torture 2009; 19: 66-87.

7. Quiroga, J, Baybuga MS. Verbal, physical and sexual abuse among children working on the street. Australian Journal of Advanced Nursing 2009; 26: 16-22.

8. Towe VL, Hasan SU, Zafar ST, Sherman SG. Street life and drug risk behaviors associated with exchanging sex among male street children in Lahore, Pakistan. The Journal of Adolescent Health 2009; 44: 222-8.

9. Kulsudjarit K. Drug problem in southeast and southwest Asia. Annals of the New York Academy of Sciences 2004; 1025: 446-57.

10. Nada KH, Suliman EDA. Violence, abuse, alcohol and drug use, and sexual behaviors in street children of Greater Cairo and Alexandria, Egypt. AIDS 2010; 24(Supp 2): S39-S44.

11. Khan AA, Khan A. The HIV epidemic in Pakistan. Journal of Pakistan Medical Association 2010; 60:300-7.

12. Leonard M. What's recreational about 'recreational rioting'? Children on the streets in Belfast. Children and Society 2010; 24: 38-49.

13. Njord L, Merrill RM, Njord R, Lindsay R, Pachano JDR. Drug use among street children and non-street children in the Philippines. Asia-Pacific Journal of Public Health 2010; 22: 203-11.

14. Balleta J, Sirvenb N, Bhukuthc A, Rousseauc S. Vulnerability to violence of girls of the street in Mauritania. Children and Youth Services Review 2011; 33: 656-62.

15. Couch J. Our lives, our say: street and working children talk about their rights in Delhi. Journal of Social Inclusion 2010; 1: 151-65. 
16. Senanayake MP, Ranasinghe A, Balasuriya C. Street children - a preliminary study. Ceylon Medical Journal 1998; 43: 191-3.

17. Jayasekara S, Prathap K. Law and the street children. 2009, Mumbai: JP Publishers.

18. Abdelgali S, Gurgel RG, Theobald S, Cuevas LE. Household and family characteristics of street children in Aracaju, Brazil. Archives of Disease in Childhood 2004; 89: 817-20.

19. Gururaj G, Girish N, Benegal V, Chandra V, Pandav R. Public health problems caused by harmful use of alcohol - gaining less or losing more?, in Alcohol Control Series. 2006, World Health Organisation, Regional Office for South-East Asia: New Delhi. 